\title{
Investigation of endophytic fungi associated with Bixa orellana l., a medicinal plant collected from western Ghats of sathyamangalam - a first report
}

\begin{abstract}
Mycoendophytes are microorganisms that reside internal tissues of living plants without causing any immediate overt negative effects, have been found in every plant species examined to date and recognized as the potential sources of novel natural products for exploitation in medicine, and agriculture with more bioactive natural products isolated from the microorganisms. In the past two decades, many valuable bioactive compounds with antimicrobial, insecticidal, cytotoxic, and anticancer activities have been successfully discovered from mycoendophytes. In the present investigation, endophytic fungi were screened form from stem, twig and leaves of Bixa orellana $L$. collected form Sathyamangalam reserve forest. Predominant endophytic fungi isolated from the medicinal plantare Phyllosticta sp., Pestalotiopsis sp., and Phomopsis sp. Statistical analysis of Shannon Diversity Index, Jaccard Similarity Coefficient, and Endophytic Infection Rate were performed to understand the nature of mycophytes in the selected medicinal plant. This is the first report on endophytic fungi documented from this medicinal plant from Sathyamangalam forest of Tamil nadu, India.
\end{abstract}

Keywords: mycoendopytes, jaccard similarity coefficient, endophytic infection rate, shannon diversity index
Volume 5 Issue 5 - 2017

Kannan KP,Ashwanandhini G, Hemasindhu B,Vinothkumar S, MadhanKumar D, Senthamarai M

Department of Biotechnology, Bannari Amman Institute of Technology, India

Correspondence: Dr. KP Kannan, Department of Biotechnology, Faculty of Biotechnology, Bannari Amman Institute of Technology, Sathyamangalam, Erode District, 63840I, Tamil Nadu, India, Email drkpkannan@gmail.com

Received: September 13, 2017 | Published: November 17, 2017

\section{Introduction}

Endophytes are present in the internal tissues of living plants occur in almost every plant on earth from the arctic to tropics, and they are rich sources for bioactive natural products. ${ }^{1-4}$ Endophytic fungi are one of the major potential sources for new useful metabolites ${ }^{5}$ Screening of diverse the endophytic fungal study may produce valuable medicinal plant products for obtaining the traditional Chinese medicine from plants on a commercial scale using microbes.6,7 In the present investigation, endophytic fungi were screened form from stem, twig, flower and leaves of Bixa orellana collected form Sathyamangalam reserve forest. Predominant endophytic fungi isolated from the selective medicinal plant are Phyllosticta Sp., Pestalotiopsis Sp., and Phomopsis Sp. Statistical analysis of Shannon Diversity Index, Jaccard Similarity Coefficient, and Endophytic Infection Rate were performed to understand the biodiversity of mycophytes in the selected medicinal plant. This is the first report on endophytic fungi documented from this medicinal plant from Sathyamangalam forest.

\section{Materials and methods}

\section{Collection of the plant materials}

Healthy plant sample of Bixa Orellana $L$ growing at various sites in the Sathyamangalam forest situated in Erode district were collected. They were brought in sterile polythene bags to the laboratory and the isolation of the fungal endophytes were commenced within 24hours of collection (Figure 1). ${ }^{8}$

\section{Isolation of endophytes}

Surface Sterilization of the plant material: The method most frequently utilized to detect and quantify endophytes involves isolation from surface-sterilized host plant tissues. Endophytic isolation was carried out under aseptic conditions. Different symptomless parts of the selected medicinal plants such as stem cuttings, leaves, and roots were used for the isolation of endophytes. The collected medicinal plant samples should be healthy and cleaned thoroughly in gentle running tap water in order to remove dirt and debris. ${ }^{9}$ The whole process of endophytic fungi be carried out aseptic condition The 50 segment of stem and leaf from each plant sample ${ }^{10}$ was cut approximately $1 \mathrm{~cm}$ by modified surface sterilization method, the leaves sample from each plant were dipped in $70 \%$ ethanol for 5 seconds, then it is immersed in $4 \%$ sodium hypo chloride for 90 seconds and finally rinsed in sterile distilled water for 10 seconds. The surface sterilized leaf samples were placed in sterile plate to remove excess moisture. For the surface sterilization of stems of each plant carried out ${ }^{11,12}$ method, in which stem segments were immersed first in $75 \%$ ethanol for 60 seconds, followed by $4 \%$ sodium hypochlorite for 180 seconds and then again in $75 \%$ ethanol for 30 seconds. $200 \mathrm{~g}$ of potato were weighed, peeled and boiled in distilled water. The filtrate of boiled potato extracts were made upto $1000 \mathrm{ml}$ with distilled water. $1000 \mathrm{ml}$ of potato extract were mixed with $20 \mathrm{~g}$ of dextrose and $20 \mathrm{~g}$ of agar. The medium is then sterilized in an autoclave at $121^{\circ} \mathrm{C}$ for 15 minutes.

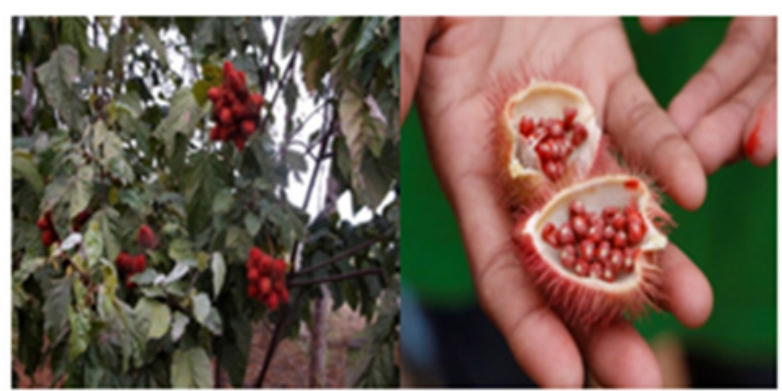

Figure I Habitat of Bixa orellana and Bixa orellana seeds. 
Inoculation of plant segments: Surface sterilized 50 segment of both leaf and stem tissues were placed in petri dish containing Potato Dextrose Agar (PDA) medium. All the plates were incubated at $28^{\circ} \mathrm{C} \pm 1^{\circ} \mathrm{C}$ to promote the growth of endophytes and were regularly monitored for any microbial growth. On observing the microbial growth, sub culturing was done. Each endophytic culture was checked for purity and transferred to freshly prepared PDA plate. To preserve as a pure culture, the endophytic fungi was inoculated in PDA slants.

Maintenance of endophytes: The purified endophytic isolates were transferred separately to PDA slants and accessioned accordingly depending upon the plant and plant parts from which they have been isolated. Finally all the purified endophytes were maintained at $4{ }^{\circ} \mathrm{C}$ till further used.

Identification of endophytic fungi: Based on the morphology of surface texture and spores at the hyphal tips which were used to identify the endophytic fungi at species level using standard manual of. ${ }^{13}$ The fungal isolates mounted on the sterile slides then it was stained with lacto phenol cotton blue and then examined in confocal microscopy. Some endophytic fungi do not produce spores and it was grouped as a one species named sterile form. ${ }^{14}$

\section{Statistical analysis}

The endophytic fungal isolates from each host plant tissue segment were analyzed based on the Percentage of density of colonization, Relative percentage occurrence of different groups of fungi ${ }^{14}$ and Percentage of Endophytic Infection Rate (EIR).

\section{Colonization frequency}

Number of species isolated

$\mathrm{CF}(\%)=$ $x 100$

Number segments screened

\section{Relative percentage occurrence (RPO) of different groups of fungi}

Relative Percentage Occurrence (RPO) of each group (viz., Ascomycetes, Hyphomycetes, Coelomycetes and Sterile forms) of fungal species in each plant species was calculated as follows:

Density of colonization of one group

$$
\mathrm{RPO}=
$$

Total Density of colonization

\section{Endophytic infection rate}

Number of infected segments

$\operatorname{EIR}(\%)=$ x 100

Total number of segments screened

\section{Biodiversity indices}

I. Shannon Diversity Index

$\mathrm{H}_{\mathrm{S}}=-\Sigma \mathrm{j}(\mathrm{pj} \ln \mathrm{pj})$

II. Shannon Evenness

$\mathrm{E}_{\mathrm{H}=} \mathrm{H} / \mathrm{H}_{\max =} \mathrm{H} \ln \mathrm{S}$

III. Relative index for Shannon

$\mathrm{H}_{\mathrm{SR}}=\mathrm{H}_{\mathrm{S}} / \mathrm{H}_{\mathrm{S} \max }=\mathrm{H}_{\mathrm{s}} / \ln \mathrm{N}_{\mathrm{i}}$
IV. Gleason index

$\mathrm{H}_{\mathrm{G}}=\mathrm{Np}-1 / \operatorname{ln~N_{\mathrm {i}}}$

V. Relative index for Gleason

$\mathrm{H}_{\mathrm{GR}}=\mathrm{H}_{\mathrm{G}} / \mathrm{H}_{\mathrm{Gmax}}=\mathrm{N}_{\mathrm{P}}-1 / \mathrm{N}_{\mathrm{I}}-1$

Where $\mathrm{N}_{\mathrm{i}}$ is the total number of individuals, $\mathrm{N}_{\mathrm{p}}$ is the number of species identified among these isolates, and $\mathrm{p}_{j}$ is the proportion of individuals in the $\mathrm{j}^{\text {th }}$ species, $\mathrm{H}_{\text {Gmax }}$ and $\mathrm{H}_{\text {Smax }}$ are the greatest possible values of $\mathrm{H}_{\mathrm{G}}$ and $\mathrm{H}_{\mathrm{S}}$ in a sample of $\mathrm{Ni}$ individuals. These maximal values are reached for $\mathrm{N}_{\mathrm{p}}=\mathrm{N}_{\mathrm{i}}$ (hence, $\mathrm{p}_{\mathrm{j}}=1 / \mathrm{N}_{\mathrm{i}}$, for all js), and equal $\left(\mathrm{N}_{\mathrm{i}}\right.$ $-1) / \ln \mathrm{N}_{\mathrm{i}}$ and $\ln \mathrm{N}_{\mathrm{i}}$ respectively.

\section{Results and discussion}

\section{Isolation of endophytic fungi from Bixa orellana $L$,}

Altogether, 300 segments (approx. $0.5 \mathrm{~cm}^{2}$ ) from each of the leaf and stem tissues of Bixa Orellana L, were sterilized and screened for the presence of endophytic fungi (Figure $2 \& 3$ ).
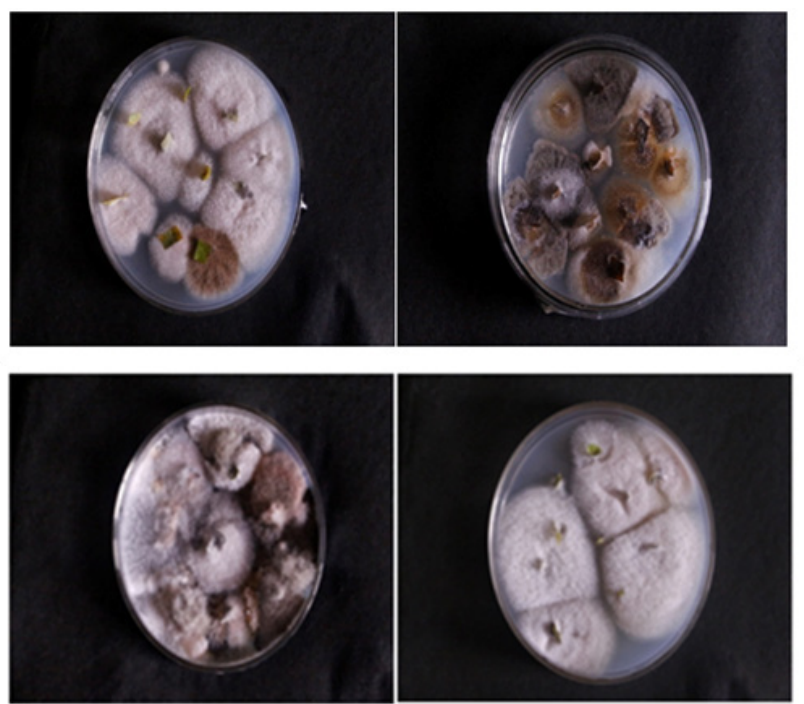

Figure 2 Endophytic Propagules Emerging out from the sterilized tissues.
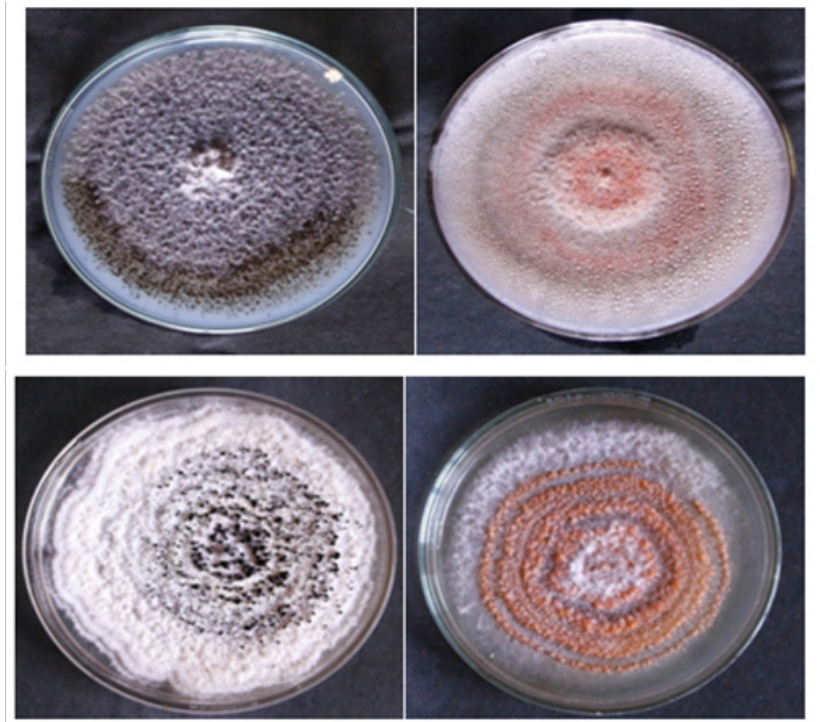

Figure 3 Petri plates showing the pure cultures of endophytic fungi identified from selected medicinal plants. 


\section{Colonization frequency of Bixa orellana $\mathbf{L}$}

Colonization frequency of Bixa orellana in leaf were dominated by Pestallotiopsis Sp. followed by Phoma Sp, Phylosticta and Nigrospora $\mathrm{Sp}$. Whereas stem was dominated by Pestalotiopsis Sp and followed by Nigrospora sphaerica, ASV02 and Chaetomium Sp. Relative percentage occurrence of Bixa orellana in Stem were dominated by Sterile forms (40\%) followed by Hyphomycetes (20\%), Coelomycetes (20\%) and Ascomycetes (20\%). Whereas Leaf was dominated by Coelomyctes (56\%), Hyphomycetes (22\%), sterile forms (22\%) and Ascomycetes were found nil. Endophytic Infection Rate of Bixa orellana leaf was found to be $100 \%$ and that of stem was 80 (Figures 4-10).

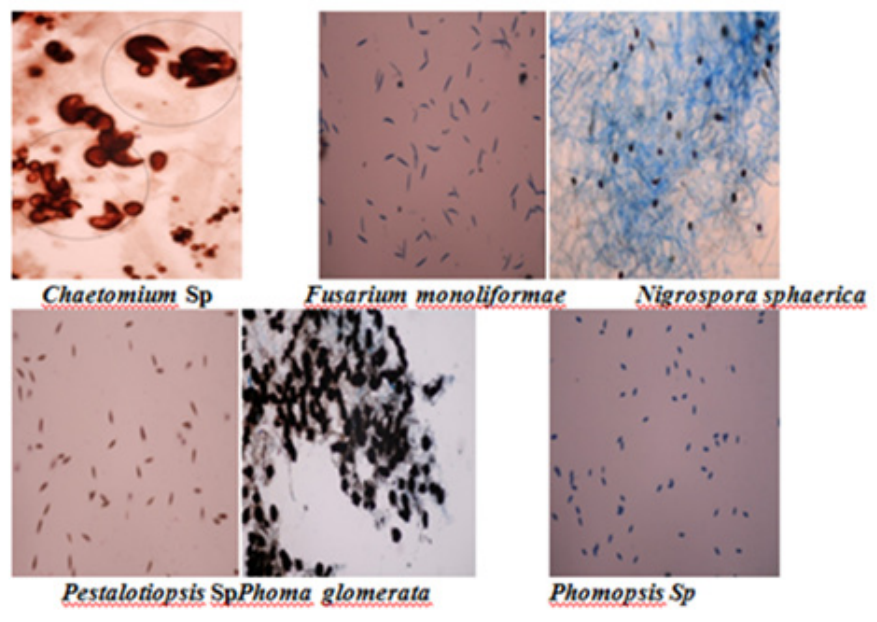

Figure 4 Micrographs of endophytic fungi reported from selected medicinal plants.

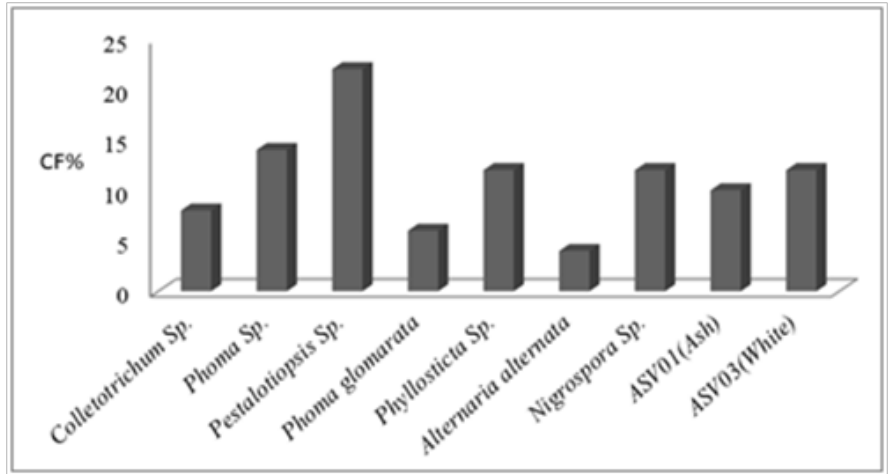

Figure 5 Colonization frequency of Bixa orellana Leaf.

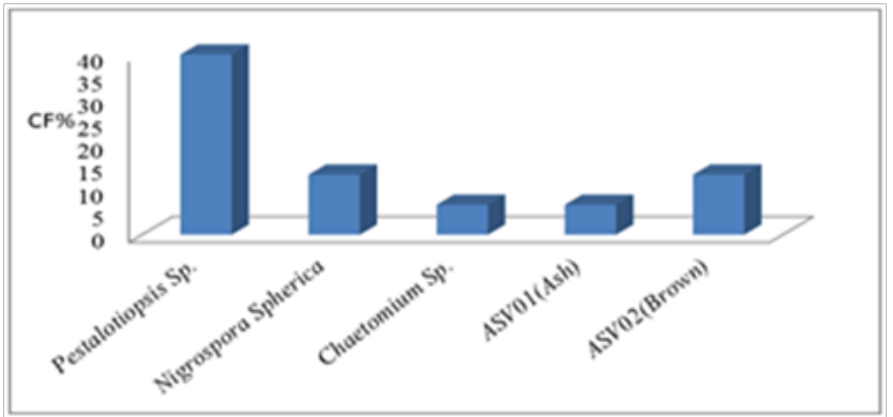

Figure 6 Colonization frequency of Bixa orellana Stem.

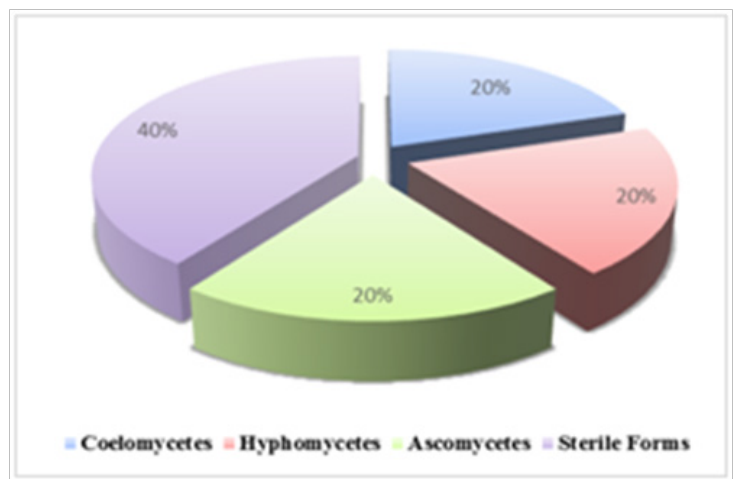

Figure 7 Relative Percentage occurrence of Bixa orellana Stem.

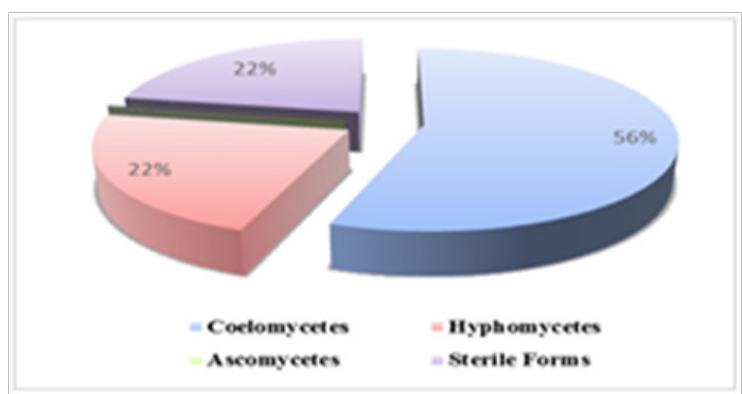

Figure 8 Relative Percentage occurrence of Bixa orellana Leaf.

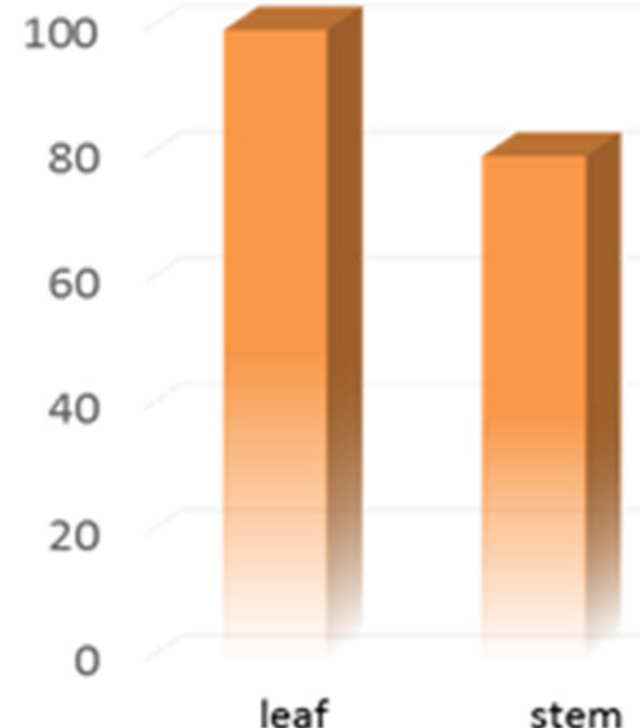

Figure 9 Endophytic Infection Rates of Bixa orellana.

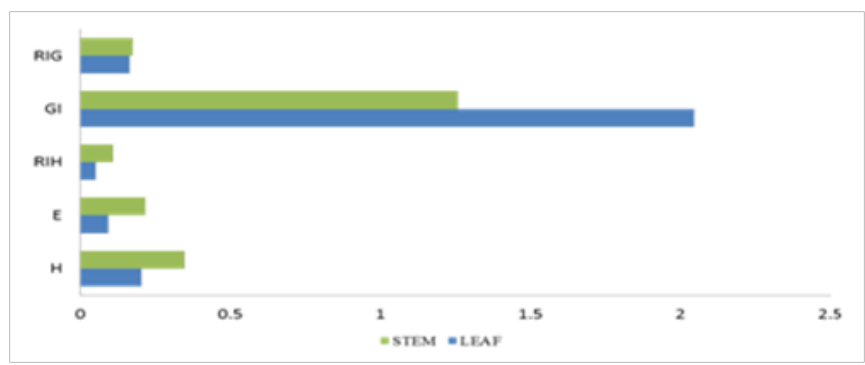

Figure 10 Biodiversity Indices of Bixa orellana. 


\section{Discussion}

One of the most interesting features of endophytic fungi is their immense diversity. There are more than one million species of endophyte globally, many of which inhabit individual leaves or other parts of the host plant. ${ }^{15}$ Tropical and subtropical regions host the largest diversity of endophytic species, since these ecosystems are the richest in plant diversity. ${ }^{16}$

According to ${ }^{17}$ the surface-disinfection of plant tissues is the most important step in the isolation process and aims to eliminate the external (epiphytic) community of microorganisms, maintaining a viable internal (endophytic) community of plant samples. The process of isolation of endophytes from surface-disinfected plant samples, with cultivation on an appropriate culture medium, has been employed by other authors. ${ }^{18-22}$ The high isolation frequencies of endophytic fungi from E. azurea $(87.86 \%)$ and E. crassipes (88.85\%) are similar to the results reported ${ }^{22}$ where $90 \%$ of leaf samples from tropical rubber trees were colonized by endophytes. Aquatic macrophytes are higher than those obtained ${ }^{23}$ were the colonization frequencies of endophytic fungi in aquatic/riparian Chinese plants varied between 18 and 63\%. The genera Alternaria and Bipolaris were the most prevalent in E. azurea and E. crassipes, respectively. The genus Alternaria comprises cosmopolitan fungi that can occur as pathogens, infecting and causing harm to several plants of economic importance, such as tangerines (Citrus reticulata), apples (Malus domestica), pears (Pyrus pyrifolia), tomatoes (Lycopersicon esculentum), and potatoes (Solanum tuberosum. In addition, Alternaria isolates have been found as endophytes in other tropical host plants. ${ }^{24-28}$

\section{Acknowledgements}

The authors would like to thank the Defense Research and Development Organization (DRDO) ER\&IPR Scheme, Government of India for financial support. Authors acknowledge the Principal, Chief Conservator of Forests, Chennai, Tamilnadu, and the conservator of Forests and Field Director, Sathyamangalam, Erode District, Tamilnadu for the permission to plant sample collection in the Western Ghats of Sathyamangalam. We, thankful to National Biodiversity Authority, Chennai for grant permission to enter the forest and also thank the Chairman, Director, Chief executive and the Principal of Bannari Amman Institute of Technology, Sathyamangalam for providing the necessary facilities.

\section{Conflict of interest} exist.

The authors of the research article declared no conflict of interest

\section{References}

1. Guo LD, Huang GR, Wang Y, et al. Molecular identification of white morphotype strains of endophytic fungi from Pinus tabulaeformis. Mycological Research. 2003;107(6):680-688.

2. Aly AH, Debbab A, Kjer J, et al. fungal endophytes from higher plants: a prolific source of phytochemicals and other bioactive natural products. Fungal Divers. 2010;41(1):1-16.

3. Aly AH, Debbab A, Proksch P. Fungal endophytes: unique plant inhabitants with great promises. Appl Microbiol Biot. 2011;90(6):18291845 .

4. Qin S, Xing K, Jiang JH, et al. Biodiversity, bioactive natural products and biotechnological potential of plant-associated endophytic Actinobacteria. Appl Microbial Bioethanol. 2011;89(3):457-473.
5. Dreyfuss MM, Chapela IH. Potential of fungi in discovery of novel low molecular weight pharmaceuticals. In: Gullo VP, editor. The discovery of Natural Products with Therapeutic Potential. UK: ButterworthHeinemann; 1994. p. 49-80.

6. Strobel GA, Daisy B. Bioprospecting for microbial endophytes and their natural products. Microbiology and Molecular Biology Reviews. 2003;67(4):491-502.

7. Schulz B, Boyle C, Draegar S, et al. Endophytic fungi: A source of novel biologically active secondary metabolites. Mycological Research. 2002;106(9):996-1004.

8. Ratnaweera PB, De Silva ED, Williams DE, et al. Antimicrobial activities of endophytic fungi obtained from the arid zone invasive plant Opuntia dillenii and the isolation of equisetin, from endophytic Fusarium sp. BMC Complement Altern Med. 2015;15:220.

9. Selvanathan S, Indrakumar I, Johnpaul M. Biodiversity of the endophytic fungi isolated from Calotropis gigantea (L). Recent Res Sci Tech. 2011;3(4):94-100.

10. Dobranic JK, Johnson LA, Alikhan QR. Isolation of endophytic fungi from eastern larch (Larix laricina) leaves from New Brunswick, Canada'. Canadian Journal of Microbiology. 1995;41(2):194-198.

11. Fisher PJ, Petrini O, Petrini LE, et al. Fungal endophytes from the leaves and twigs of Quercus ilex L. from England, Majorea and Switzerland'. New Phytol. 1994;127(1):133-137.

12. Fisher PJ, Petrini O, Sutton B. A comparative study of fungal endophytes in leaves, xylem and bark of Eucalyptus nitens in Australia and England. Sydowia. 1993;45:338345.

13. Suryanarayanan TS, Senthilarasu G, Muruganandam V. Endophytic fungi from Cuscuta rejlexa and its host plants. Fungal Diversity. 2000;4:117-123.

14. Sutton BC. The Coelomocytes-Fungi Imperfect with pycnidia, acervuli and stromata. UK: Common wealth Mycological Institute; 1980.

15. Suryanarayanan TS, Thennarasan S. Temporal variation in endophytic assemblages of Plumeria rubra leaves. Fungal Diversity. 2004;15:197204.

16. Arnold AE, Lutzoni F. Diversity and host range of foliar fungal endophytes: are tropical leaves biodiversity hotspots? Ecology. 2007;88(3):541-549.

17. Banerjee A, Duflo E, Glennerster R. The miracle of microfinance? Evidence from a randomized evaluation. Bread Working Paper, 2010:278.

18. Araújo JM, Silva AC, Azevedo JL. Isolation of endophytic actinomycetes from roots and leaves of maize (Zea mays L.). Braz Arch Biol Technol. 2000;43(4):447-451.

19. Araújo WL, Maccheroni W, Aguilar-Vildoso CI, et al. Variability and interactions between endophytic bacteria and fungi isolated from leaf tissues of citrus rootstocks. Can J Microbiol. 2001;47(3):229-236.

20. Gazis R, Chaverri P. Diversity of fungal endophytes in leaves and stems of rubber trees (Hevea brasiliensis) in Peru. Fungal Ecol. 2010;3:240 254.

21. Sakayaroj J, Preedanon S, Supaphon O, et al. Phylogenetic diversity of endophyte assemblages associated with the tropical seagrass Enhalus acoroides in Thailand. Fungal Diversity. 2010;42(1):27-45.

22. Pamphile JA. Antimicrobial Activity of Crude Extracts of Endophytic Fungi Isolated from medicinal plant Sapindus saponaria L. Journal of Applied Pharmaceutical Science. 2012;2(10):35-40.

23. Rhoden SA, Garcia A, Bongiorno VA, et al. Antimicrobial Activity of Crude Extracts of Endophytic Fungi Isolated from medicinal plant Trichilia elegans A. Juss J App Pharm Sci. 2012;2(8):57-59. 
24. Gazis R, Chaverri P. Diversity of fungal endophytes in leaves and stems of rubber trees (Hevea brasiliensis) in Tambopata Peru. Fungal Ecol. 2010;3:240-254.

25. Li M, Chang M, Zhang Q, et al. Endophytic fungus strain ZD6 isolated from the stem of Bruguiera gymnorrhiza and the antibacterial activity of its metabolites. Junwu Xuebao. 2010;29:739-745.

26. Sakayaroj J, Preedanon S, Supaphon O, et al. Phylogenetic diversity of endophyte assemblages associated with the tropical seagrass Enhalus acoroides in Thailand. Fungal Diversity. 2010;42(1):27-45.
27. Garcia A, Rhoden SA, Bernardi Wenzel J, et al. Antimicrobial activity of crude extracts of endophytic fungi Isolated from Medicinal Plant Sapindus saponaria. Journal of Applied Pharmaceutical Science. 2012;2(10):35-40

28. Orlandelli $\mathrm{RC}$, Alberto $\mathrm{RN}$, Almeida $\mathrm{TT}$, et al. In vitro antibacterial activity of crude extracts produced by endophytic Fungi Isolated from Piper hispidum Sw. Journal of Applied Pharmaceutical Science. 2012;2(10):137-141. 